\title{
4. Citizens and Governments: Getting closer or further apart?
}

\author{
Rolf Alter
}

Whether governments connect with their citizens and how they do so is, as it has been in the past, a prominent subject in the public governance debate across the group of Organisation for Economic Co-operation and Development (OECD) nations. The 2011 Australia and New Zealand School of Government (ANZSOG) national conference on 'Putting Citizens First: Engagement in Policy and Service Delivery for the 21 st Century' is a prominent example of taking a fresh look at a known subject. Answering the question of why there is such renewed interest requires consideration of several issues.

\section{Unfinished business of managing engagement}

Previous arguments and discussions around 'citizens first', 'focus on citizens' or 'citizen-centered government' have remained inconclusive to a large extent. In a recent comprehensive assessment by the OECD, Focus on Citizens: Public engagement for better policy and services, ${ }^{1}$ participating countries reported mixed progress in applying the 'guiding principles' for information, consultation and active participation in policy-making which had been developed by the OECD in 2001. Overall, governments appear to have concluded that they had established rights, had active citizens and had a commitment to engage them in policy-making, but faced challenges of resources, time and lack of evaluation (Figure 1).

The report identified a number of remaining challenges for governments that do not seem to have lost any relevance in ensuing years since the publication's release. These include:

- How to design cost effective and useful public consultation and engagement initiatives.

- How to make public policy more interesting and relevant to more people.

- How to earn and keep people's trust that government will actually use their input.

1 OECD. 2009. Focus on Citizens: Public engagement for better policy and services. Paris. 
- How to address the time constraints that characterise modern urban societies in OECD countries.

- How to raise the impact of evaluation on ongoing learning and continuous quality improvement of participation processes.

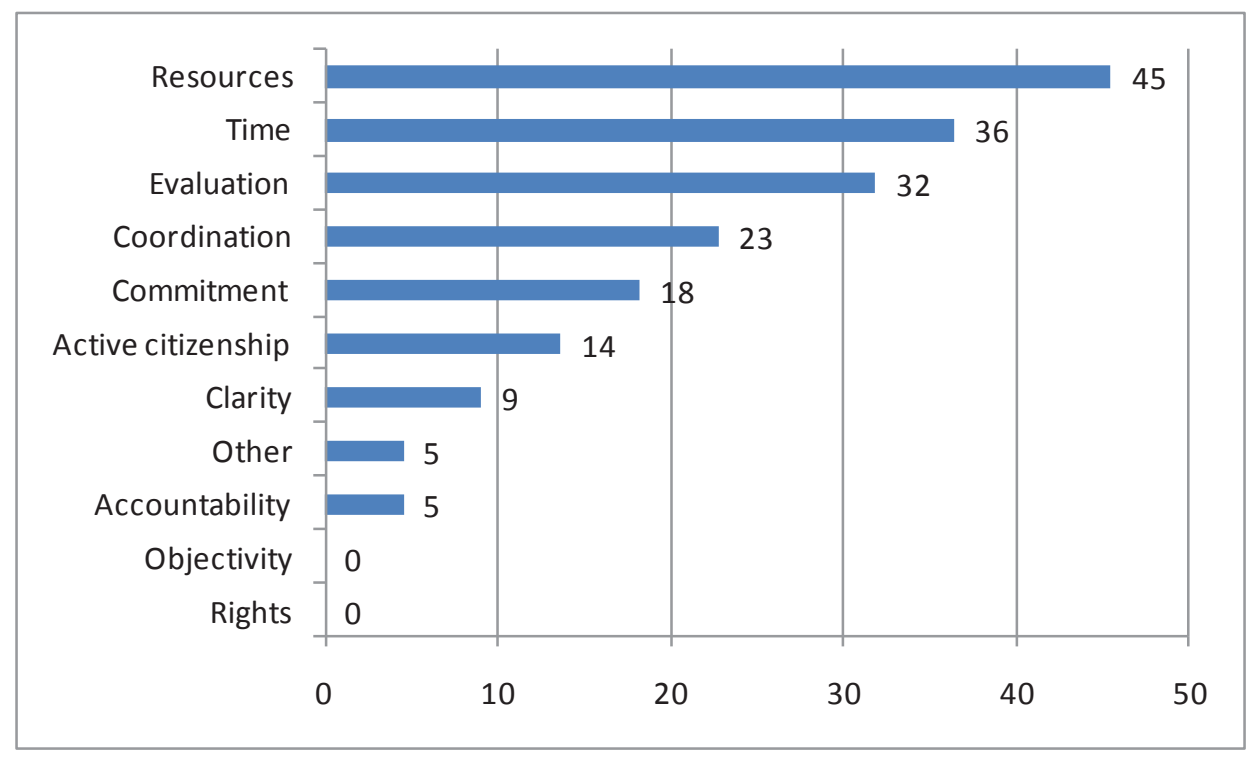

Figure 1: Principles which are the most difficult to meet (\% respondents, $\mathrm{n}=\mathbf{2 5}$ countries)

$\%$ respondents ranking the option as 'important' or 'very important'.

Source: OECD. 2009. Focus on Citizens: Public engagement for better Policy and services. Paris.

\section{New opportunities through information technology}

The answers to some of these questions may be found in recent information technology (IT) developments. The rapidly accelerating promise of IT to provide an unlimited potential of dialogue and interaction with citizens is making electronic-based initiatives a standard feature of most - if not all — public sector reform programs. An overview of country initiatives published by the $\mathrm{OECD},{ }^{2}$ pointed to growing expectations for technology and social media to be a critical channel for governments to inform their citizens, as well as facilitating citizens' access to government.

2 OECD. 2011. The Call for Innovative and Open Government: An overview of country initiatives. Paris. 
Despite some progress, however, challenges remain. Effectively mobilising citizens around policy design and service delivery requires: solutions for the associated implications for the back office, the effective monitoring of citizen mobilisation, and the demonstration to citizens of a return by government to a focus on the quality of policy performance. The search for and exchange of positive experiences in responding to these challenges are important tasks that are still to be addressed.

\section{Changes in the economic and social environment}

Revisiting the government-citizen relationship would be incomplete without taking into account other important associated developments, some of them relatively recent. Such examples include:

- The 'Arab Spring' of 2011, in which citizen awakening in Tunisia and Egypt subsequently spread throughout North Africa, the Middle East, and eventually to Europe and the United States. Such 'global indignation's is adding a new quality and quantity to the involvement of citizens with government.

- The call for a new balance between governments and markets which emerged in the wake of the economic crisis of 2008-2009, but seems to have fallen victim of powerful interests.

- The impact of fiscal consolidation on public policies to deliver growth and public services.

I would like to focus my comments on these three factors, as I believe they are particularly relevant in addressing the question of governments and citizens being driven apart or drawing closer together.

In these three case studies, one can easily identify arguments and observations that would support the hypothesis of a widening gulf between citizens and governments, as much as there are those that provide evidence of a closer relationship. Exploring these countervailing tendencies should help establish realistic expectations of governments, and encourage discussion of instruments and policies for greater dialogue, effective participatory policy design and more space for citizen involvement in service delivery. There may also be a need to assess some more fundamental implications for the future role of government and governance arrangements. Consider now the three case studies.

3 Gideon Rachman. 2011. Financial Times, 30 August, p. 7. 


\section{Citizen engagement: Now on their terms?}

If there were any doubts about the potential, scope, willingness and ability of citizens to engage with governments, the awakening of Arab societies across the Middle East and North Africa in 2011 provides some forceful arguments against them. All the more so, as this so-called 'Arab Spring' (which lasted into summer, autumn and winter) is inspiring a growing number of citizen movements in other countries with diverse economic, social or political systems. In exploiting the potential of IT — including access to social media — citizens are organising themselves to reshape political debate, press for political decisions and even effectuate regime change. The participants in this 'global indignation' determine the terms of interaction with governments, connect in ways and by means of their choice and are proactive rather than reactive to invitations by governments for dialogue.

That isn't to say IT solutions are critical to the success or even presence of such movements. Powerful examples of effective citizen engagement arose long before the arrival of the information society as we experience it today, such as the many uprisings against Communist regimes in Eastern Europe. Moreover, not all today's movements are necessarily constructive in terms of policy design or better policies.

They all, however, are characterised by the fact that governments are no longer necessarily in the driver's seat of citizen engagement - nor do they have to be. This is not to belittle their serious and creative efforts to mobilise citizens through sophisticated consultation processes, open-government policies or co-operative ways of public service delivery. Data on outsourcing and coproduction show that governments have in fact moved significant resources to buy or pay for non-government entities to provide 'public services' (Figure 2).

While governments are aware of citizens becoming increasingly sophisticated 'clients' of theirs, replicating their experience as consumers, the qualitative change to 'emancipated' citizens is probably a new phenomenon for most governments. Citizens not only set their own agenda, and demand policy action, they also suggest solutions and call for results from governments. More often than not, these are in time spans that are unfamiliar for almost all governments and public administrations.

Keeping up with the emancipated citizen is not only a challenge for the executive branch of governments. The traditional forms of democratic participation - be they through political parties, and the representation of citizens in parliaments - are facing similar challenges, including being bypassed, or having their monopoly as the voice of the people undermined. 


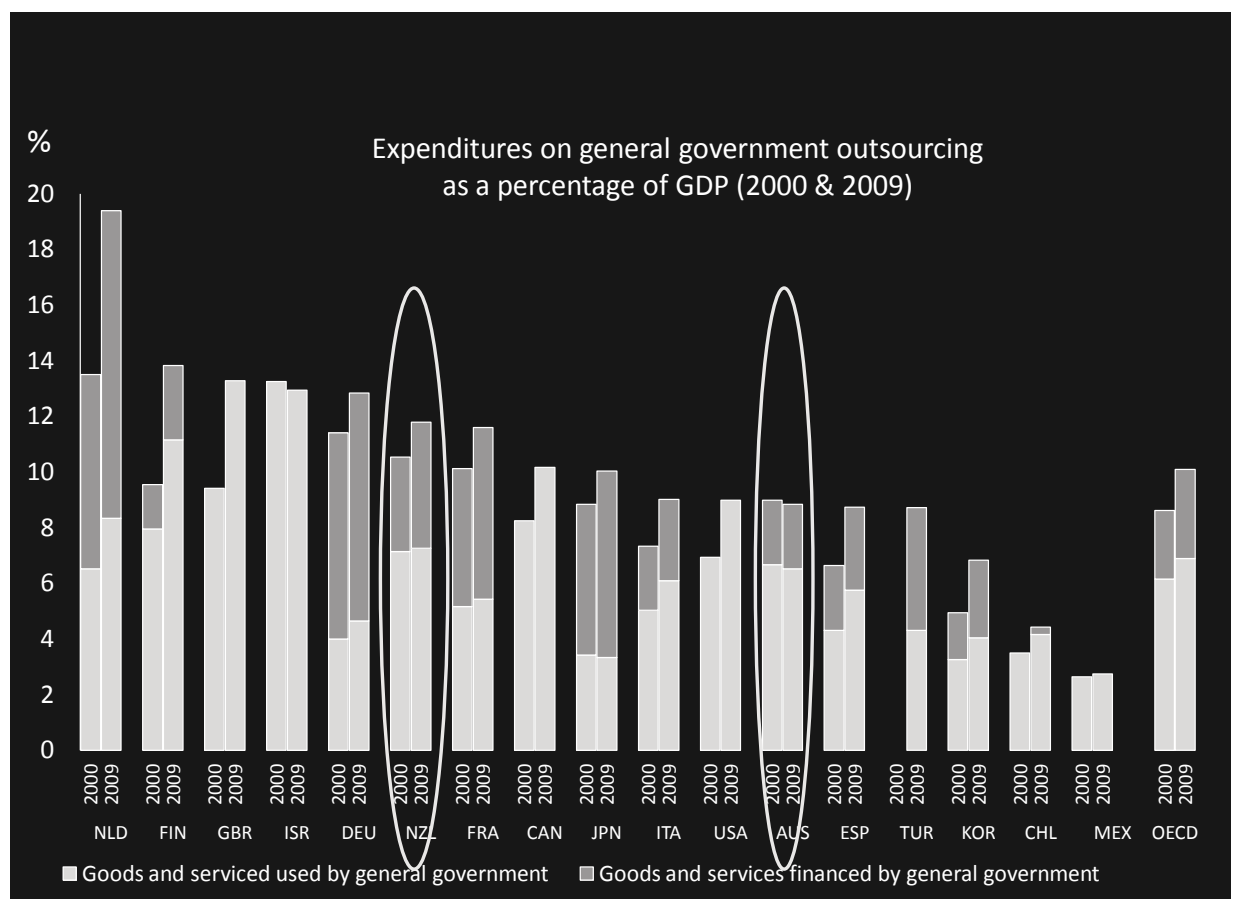

Figure 2: Expenditures on general government outsourcing as a percentage of GDP (2000 \& 2009)

Source: Government at a Glance, OECD, 2011.

But is it only the emancipated citizen that challenges governments and parliaments? Vested interests and entrenched rent-seekers (i.e., actors who manipulate the political environment to extract 'economic rent' for themselves) have been joined by a range of other pressure groups, often so-called 'one-issue' movements. Lobby groups, or the media, are seen to exert a disproportionate influence over events.

In light of events that occurred across the Arab world in 2011, governments everywhere must ask themselves some important questions: How did we get to this awakening - beyond the facilitating factor of technology? How do we respond to legitimate and illegitimate pressures from vested interests? What are the implications for public policy design and public service delivery? How does it impact on the functioning of protective and/or developmental democracy which can be found in OECD countries, and how do we remedy any negative repercussions? 
Putting Citizens First

\section{From modifying the 'social contract' to a new balance between markets and governments?}

In the post-1945 world, across the OECD, the notion of the welfare state emerged with a priority to guarantee a minimum standard of living to all citizens through the provision of public services to all sectors of society. The social contract included the state's responsibility for preserving citizens' rights, guaranteeing social protection and ensuring civic liberties. While the exact terms of the social contract differed among countries, they all presented some mix of protective and developmental democracy.

The radical, very visible change in policies in the United Kingdom towards 'deregulation' of the economy in the 1970s could be interpreted as the starting point of a long term, gradual reduction of the role of the state in managing the economy and society. The neo-liberal school advocated and helped make reality a situation in which previously public goods became private ones, be it in the areas of public infrastructure of roads, railways, ports or airports, or in utilities, including telecommunications, water and power. At a later stage of this transition process, citizens were given the 'right to choose', or were entrusted with the responsibility to take care of their old age pensions, their health coverage or the education of their children.

While this growing privatisation of public services was driven by the promise of greater efficiency through private sector involvement, one may question whether it also contributed to a 'loser' relationship between citizens and government. With a multiplicity of service providers, the challenge of maintaining common standards in servicing citizens in health, education, security and safety emerged. Could citizens perceive government as abdicating its responsibilities, with important consequences in terms of their overall accountability?

If governments were no longer - or not to the same extent - guaranteeing access to public services, why should citizens' behaviour not change as well? If citizens were to interpret the gradual withdrawal of the state as an attempt to modify the social contract, governments would become just one of the players in the networks of individual citizens. Why then engage with the government more than with others? In fact, one could formulate the hypothesis that governments invented their commitment to 'focus on citizens' in response to the disenfranchisement of citizens from their governments through the earlier drive of privatisation of public goods.

The crisis of 2008/2009 did not help in this respect. A forceful, co-ordinated response of countries at the G20 level to avoid the global economic disaster 
seemed to indicate the return of the state as the most powerful potential actor in steering markets and economies. Despite the nearly unanimous call from politicians and citizens for re-establishing a better balance between markets and governments, however, not much has happened in terms of re-establishing the counterbalancing weight of proactive states. Instead, equity among citizens deteriorated further, unemployment rose and stays at unprecedented levels in many OECD countries, both in aggregate and structural terms.

Citizens are witnessing this lack of effective governance, contributing to a further loss of trust in governments meeting their part of the social contract. According to a nationwide poll carried out in the United Kingdom by IPSOS MORI (in 2011), just one person in six - 17 per cent - professed to trust government ministers. According to the same survey, doctors are the most trusted profession - politicians the least trusted.

Against this background, two tendencies could be particularly important when governments review the potential and constraints for engagement initiatives. On the one hand, the tendency of greater individualism in society is reducing the scope and impact of organised collective action and the search for shared public interest. Individual interests are replacing collective interests as driving forces for change. Evidence is increasing to suggest that when a citizen's selfinterest is concerned, they are less likely to engage in pro-social behaviour. Growing inequality introduces another divide: between those who can afford or even benefit from less government and those who need more government urgently because of the economic and social stress of unemployment, age, illness or indebtedness. On the other hand, the question may be raised whether the powerful emergence of civil society is the response of citizens to organise themselves - and an indication of a breakdown in the traditional ways that representative democracy is practiced.

So, how are citizens kept close to governments in light of a continuing modification of the social contract? Should governments put the emphasis in their engagement initiatives on mobilising civil society rather than citizens? In this case, how is this achieved while avoiding the pitfalls of lack of representativeness and the dominance of vested, often one-issue driven interests? How is the civil society model to be reconciled with representative parliamentary systems? How does one exercise leadership in the pursuit of the public interest, which remains the only approach when it comes to climate change, for example? 
Putting Citizens First

\section{Fiscal consolidation: Co-production as exit strategy for public service delivery?}

Fiscal pressures to reduce operating expenditures and to cut program spending are a reality in the majority of OECD countries. Budgetary constraints impose increased transparency in the way governments use public funds. They create momentum for innovative solutions and a rethinking of traditional forms of service delivery, which could, in principle, give citizens more control of their lives. Certain innovations push the boundaries of public service provisions to citizens by defining new forms of public involvement, as documented in the OECD's publication Together for Better Public Services: Partnering with citizens and civil society. ${ }^{4}$

The rethinking of traditional public service delivery in a new socio-economic environment transforms the relationship between service users and providers, enabling user control and ownership. While still at a developmental stage in many areas of public service delivery, co-production has started to be mainstreamed in health and social care.

Important challenges, however, exist: quantification of the potential savings; assessment of unintended consequences whereby costs and accountability are shifted onto users and citizens; management capacity at the local level, where most public services would be 'co-produced'; consequences for accountability of policy-makers and risk management in the case of failures of co-production. These are just some of the issues that require intensive analysis and exchange of experiences to test the reality of a new model, which, in principle, could bring governments and citizens closer together, while respecting their mutual responsibilities.

One of the important requirements for a successful new foundation of the government-citizen relationship would be to dispel the suspicion that calls for greater citizen involvement are not driven by the desire to enhance participation, innovation and democracy, but, rather, simply reflects the reality of reduced public resource availability. Nor the even worse belief that co-production is an expression of the belief in the benefits of reducing the state as an objective (of ideology) in itself.

A recent survey by the OECD is not encouraging: the demand for partnerships is predominantly coming from within governments, while citizens and service users are less interested in those sorts of arrangements (Figure 3).

4 OECD. 2011. Together for Better Public Service: Partnering with citizens and civil society. Paris. 


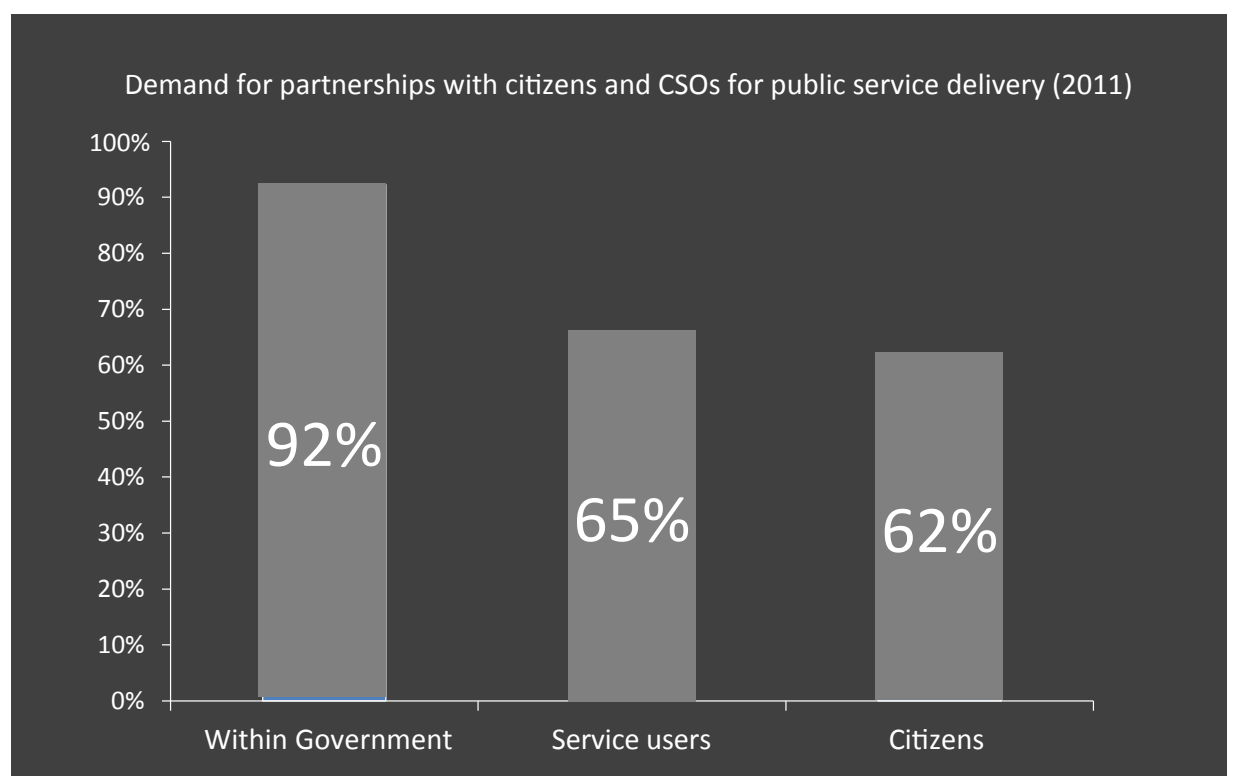

\section{Figure 3: Demand for partnerships with citizens and CSOs for public service delivery (2011)}

Source: Together for Better Public Services-Partnering with Citizens and Civil Societies.

There is an unfortunate precedent of a misalignment between government and citizen expectations. The quick and firm actions by governments to re-establish confidence, maintain capacity and boost their economies in 2008/2009 were mostly done with very limited or no consultation with citizens, leading to a sense of frustration in not having being invited to decisions that affect the interests of citizens for many years to come. This lack of opportunity for participation - a situation which was felt even by many parliamentarians - may partly explain contemporary resistance to the fiscal consolidation plans of governments. Today, citizens are not fully informed, they do not see the consequences and they do not endorse policy decisions. Essentially, they do not want to be close to their government because their government is not close to them.

\section{Conclusions}

Policy-makers in OECD countries and beyond broadly believe that facilitating participation of citizens might enhance democratic engagement, build trust in government and harness productive forms of responsibility, including in the delivery of public services. While the intrinsic value of participation is beyond doubt, the business case is still to be made. More work, and more opportunities for the exchange of practical experience is required. 
If governments want to intensify their call on citizens' engagement, it is advisable that they take into account some of the more recent developments which affect the relationship between citizens and governments, in particular the demonstrated importance of social media in the 'awakening' of societies, the erosion of the social contract and the impact of fiscal consolidation measures.

Such broader approaches would put the review of citizen engagement into a wider perspective. Ensuring the re-engagement of governments and citizens requires:

- Better assessment of where the demand for engagement comes from and under which conditions citizens are ready to engage.

- Thinking more thoroughly about the objectives to be achieved from a strong relationship with citizens: for example, how is participation balanced with efficiency, and participation with equity? And how can participation bring innovation to government?

- Reviewing of the institutional structures of government. Does strengthening the dialogue with civil society, for instance, lead to the weakening of parliaments? How is a balance found in this tri-lateral relationship? And how could fiscal institutions, such as fiscal councils or parliamentary budget offices, which are being set up in many OECD countries (including Australia), be helpful in this respect?

- Assessment of the current approach to reforms of the public sector, including the new public management reform paradigm. Have the 'technical' management improvements of the 'new public management' - efficiency rather than effectiveness; technocratic virtues rather than those of build, communicate and implement - run their course, at least at the conceptual level, even if improvements in implementation can still be made?

The discussion of the relationship between citizens and governments will continue, especially in times of serious economic, social and environmental challenges. Many, more fundamental, reflections are being launched about the appropriate model of societies and the role of the state in the 21 st century. Has the time of a new governance reform come? 